\title{
Creation of a synthetic indicator of quality of care as a clinical management standard in primary
} care

Ermengol Coma ${ }^{1,2^{*}}$, Manel Ferran ${ }^{3}$, Leonardo Méndez ${ }^{1,2}$, Begoña Iglesias $^{4}$, Francesc Fina ${ }^{1,2}$ and Manuel Medina ${ }^{1,2}$

\begin{abstract}
Introduction: The development of electronic medical records has allowed the creation of new quality indicators in healthcare. Among them, synthetic indicators facilitate global interpretation of results and comparisons between professionals.

Methods: A healthcare quality standard (EQA, the Catalan acronym for Estàndard de Qualitat Assistencial) was constructed to serve as a synthetic indicator to measure the quality of care provided by primary care professionals in Catalonia (Spain). The project phases were to establish the reference population; select health problems to be included; define, select and deliberate about subindicators; and construct and publish the EQA.

Results: Construction of the EQA involved 107 healthcare professionals, and 91 health problems were included. In addition, 133 experts were consulted, who proposed a total of 339 indicators. After systematic paired comparison, 61 indicators were selected to create the synthetic indicator. The EQA is now calculated on a monthly basis for more than 8000 healthcare professionals using an automated process that extracts data from electronic medical records; results are published on a follow-up website. Along with the use of the online EQA results tool, there has been an ongoing improvement in most of the quality of care indicators.
\end{abstract}

Conclusions: Creation of the EQA has proven to be useful for the measurement of the quality of care of primary care services. Also an improvement trend over 5 years is shown across most of the measured indicators.

Keywords: Health care quality indicators, Primary care, Feedback

\section{Background}

One of the priorities of health systems is ensuring the quality of primary care (Nietert et al. 2007). To achieve this objective, multiple indicators have been developed to assess the quality of clinical practice (McColl et al. 1998). Nonetheless, utilization of numerous partial indicators makes it difficult to achieve a global interpretation and to compare individuals as well as groups or centres. In many situations, the use of fewer but more comprehensive indicators is preferable. Along this line, some composite, or synthetic, indicators have been defined that condense the measurement of several subindicators

\footnotetext{
* Correspondence: ecomaredon@gencat.cat

'Institut Català de la Salut (ICS), Gran Via de les Corts Catalanes, 587-589, 08007, Barcelona, Spain

${ }^{2}$ IDIAP Jordi Gol (Primary Health Care Research Institute), Gran Via de les Corts Catalanes, 587, 08007, Barcelona, Spain

Full list of author information is available at the end of the article
}

into one value, thereby facilitating interpretation and better representing the process of healthcare delivery (Saturno 2004). The possibility of summarizing quality of care in one measurement has made these synthetic indicators very attractive for comparisons between different centres and professionals. Among other characteristics, good health indicators should be valid, evidencebased, comparable, modifiable, directed toward health problems of importance due to their severity or frequency in primary care patients, feasible to obtain without overburdening the healthcare professional and finally, they must deliver health benefits to the population with minimal secondary effects (Brown and Lilford 2006; NHS Institute for Innovation and Improvement). One of the circumstances that has especially favoured this process of constructing synthetic indicators has

\section{空}

(C) 2013 Coma et al.; licensee Springer. This is an Open Access article distributed under the terms of the Creative Commons Attribution License (http://creativecommons.org/licenses/by/2.0), which permits unrestricted use, distribution, and reproduction in any medium, provided the original work is properly cited. 
been the development of electronic medical records and the availability of tools to manage large databases.

In recent years there has also been increasing international interest in "pay for performance" programmes for individual health professionals (Gérvas and Pérez 2008) and in the development of evidence-based synthetic indicators to objectively measure clinical performance. In 1994 this new payment method began in Australia (Medicare Australia) and has been extended to Canada (Pink et al. 2006), the United States (Rosenthal et al. 2005), New Zealand (Perera et al. 2007) and the United Kingdom (Roland 2004; Doran et al. 2006), among others (Gérvas and Pérez 2008; Doran et al. 2008; Engels et al. 2005). Some of these systems have incorporated several different models of clinical indicators. The most well-established effort is that of the National Health Services (NHS) of the United Kingdom, which in 2004 developed the Quality Outcomes Framework (QOF), a payment system for primary care physicians. This system facilitates a single quality measurement that distributes 1000 points across four domains (Roland 2004; Doran et al. 2006; Lester and Majeed 2008). In the United States, there are also systems of clinical indicators that measure outpatient care (Rosenthal et al. 2005; The Ambulatory Care Quality Alliance Recommended Starter Set). One of these systems is the Summary Quality Index (SQUID), a composite measure of the quality of primary care that consists of 36 quality indicators related to a variety of fields and supported by a solid scientific base (Nietert et al. 2007). As has occurred in other environments, utilization of electronic medical records in primary care is widespread in Spain, but there is no global system to describe the clinical performance of healthcare professionals and centres. However, at a more local level, very useful and well-structured efforts have been observed, such as that in Tarragona province (Catalonia) which selected 10 health problems in primary care that became a standardized 17-item scale of healthcare quality (Vila et al. 2006).

The Catalan Health Institute (Institut Català de la Salut, ICS) is a public enterprise of the Generalitat de Catalunya, the Catalan government. It is the primary provider of primary care services and covers approximately $80 \%$ of the population ( 5800000 patients). Beginning in 2005, a series of circumstances combined to encourage administrators to pay greater attention to measuring clinical quality. First, the process of computerizing medical records was practically completed. All primary care practices now routinely enter clinical data in a software application called e-CAP (Estació Clínica d'Atenció Primària), the electronic medical records system for primary care in Catalonia. Secondly, there was a growing effort to incentivize healthcare professionals within a framework of variable, evidence-based compensation known as "pay for performance" (Cortés Pérez et al. 2009; Iglesias Pérez et al. 2008). This led to a need for a standard, homogeneous quality measure for health professionals who provide patient care (Fina Avilés et al. 2010). Initially, then, the established priority was to design a synthetic indicator to base healthcare on the best available scientific knowledge and focus attention on the patient; eventually the indicator also became a tool in "pay for performance" determinations for doctors and nurses (Peiró 2004).

This article describes the construction and shows the results of the healthcare quality standard known as the EQA (Estàndard de Qualitat Assistencial, the Catalan acronym for Healthcare Quality Standard), a synthetic indicator designed to measure the quality of care provided by primary health care professionals and serve as a useful tool to improve clinical practice.

\section{Methods}

The EQA is a synthetic indicator that combines distinct clinical subindicators. It was designed between May and December 2006 and the objective was to obtain an indicator that would measure quality of care provided to a population assigned to a primary care team (PCT). Later, in 2007 , a series of changes in methodology were implemented and these have remained in effect. The subindicators comprising the EQA are calculated by the Information System for Primary Care Services (SISAP), which draws information directly from the e-CAP software.

The methodology for the construction of the EQA included: 1) Establishment of the reference population and the theoretical basis for the standards; 2) Selection of health problems to be included in the EQA; 3) Definition of subindicators; 4) Selection of subindicators; 5) Deliberation about the subindicators and final construction of the EQA; and 6) Publication of EQA results.

\section{Establishment of the reference population and theoretical principles}

Initially, the reference population for the EQA was the population assigned to a PCT. Later, this population was modified and beginning in 2008 was defined as the population assigned to and receiving attention from a PCT at least once in the preceding three years for any reason. Each subindicator included only those patients who met specific criteria. For example, a subindicator that determines the proportion of patients treated with beta-blockers only makes sense in a restricted population such as patients with ischemic heart disease, or a subindicator that monitors glycated haemoglobin should only include patients with diabetes mellitus.

On the other hand, the theoretical principles that frame the design of the EQA were: a) To encourage quaternary prevention and avoid overtreatment; b) To provide global information about clinical practice in primary care; c) To 
combine the best available tests with professional judgment in defining the subindicators; and d) To guarantee the quality of the subindicators and the feasibility of collecting them from the electronic medical record.

\section{Selection of the health problems}

Construction of the subindicators that comprise the EQA was based on a quantitative analysis of the health problems most frequently treated in primary care, both in the population older than 14 years and in the paediatric population. This included an analysis of the diagnoses codified in the visits by family physicians, paediatricians or nurses at all of the ICS primary care sites from January through December of 2006 (4. 680706 users and a total of 23327557 visits).

\section{Definition of subindicators}

Once the health problems had been selected, following a Delphi methodology, we asked at least two experts on each diagnosis to formulate a clinical management indicator. Instructions were sent by e-mail, along with a standard form to collect the following information for each indicator: definition of the indicator, numerator, denominator, target age group and evidence level, according to the North of England Evidence Based Guideline Development PROJECT (Eccles et al. 1998).

\section{Selection of subindicators}

All of the proposed indicators underwent a structured review by two groups of evaluators based on the criteria of validity, reliability, ease of calculation and scientific evidence. The first review used a paired comparison process in which two evaluators, independently and using the established criteria, accepted or rejected the indicators. In the case of disagreement, a decision was taken by consensus of the entire group of evaluators. All of the selected indicators were then submitted to a new consensus review by a second group of evaluators. To maintain a certain stability in the calculation of indicators, an annual review process was established; immediate application of modifications would occur only if an error in design or calculation were detected or new evidence appears that justifies such a change.

\section{Deliberation about subindicators and final construction of the EQA}

After selecting the indicators, a new revision was made with the following objectives: to group similar indicators; to link indicators to health problems and to remove prevalence indicators because all indicators were adjusted by detection.

Evaluators also assigned the appropriate weight that each of them would have in the final computation of the EQA. This deliberation involved a multidisciplinary group of primary care professionals, who based their consideration on previously defined criteria of severity ( 0 to10 points), magnitude (0-10), impact of primary care $(0-5)$ and effectiveness (0-5) (NCMC: non-compensatory multi-criteria approach).

Finally, the EQA was constructed as a synthetic indicator that assigns a global score on a scale of 0 to 1000 points, i.e., the sum of the scores obtained on the subindicators comprising the standard. All of the subindicators are calculated to produce a global score for each PCT and most of them are also calculated for each professional. Whenever possible, the indicators combine the quality of care and disease detection in one sole measure (see Additional file 1 for more details about EQA calculation). For each subindicator, a minimum value was also established at the beginning of 2007, corresponding with the $20^{\text {th }}$ percentile of the distribution. Below this value, 0 points are assigned on that indicator. Similarly, an optimum value is set that corresponds with the $80^{\text {th }}$ percentile of the distribution, beyond which the maximum value for that indicator is assigned. Between these two values, a score between $0.1 \%$ and $99.9 \%$ of the maximum possible score was determined. The score for the indicator resulted from the sum of all the partial scores assigned to each of its subindicators. Therefore, the results of the subindicators comprising the EQA are now compared with minimum and maximum targets established in January of each year, based on the $20^{\text {th }}$ and $80^{\text {th }}$ percentiles of the results over the previous 12 months. In addition, each primary care professional or team has an individual target on the synthetic indicator that is drawn from the baseline score and rewards efforts to improve.

\section{Publication of the EQA results}

Once the EQA was constructed, primary care professionals and teams could consult their clinical indicators from their workstations. These look-ups left a record in the information system that allowed us to determine that professionals were accessing their results to see whether they were meeting their patient care goals. Since 2007, the information has been updated monthly and results for each professional compared with his or her surroundings (e.g., for that entire PCT or the average levels and total results for all ICS PCTs) and with their baseline scores. Results are colour coded to facilitate both their interpretation and an assessment of the professionals' response. Whenever possible, in addition to numeric scores, each professional can view a list of patients who are not meeting the established criteria for EQA indicators, with the objective being to review those cases individually.

\section{Results}

\section{Construction of the EQA}

For the different phases of constructing the EQA, participation included 107 healthcare professionals, 73 of 
whom took part in defining the subindicators and 34 in the later selection and deliberation phases and the final construction of the synthetic indicator.

\section{Selection of the health problems}

Health problems that represented the $80 \%$ of the demand for medical attention in primary care were selected. These ICD10 codes were gathered in 91 health problems groups according to physiological, anatomical and etiological criteria (between 1 and 9 codes per group). For more information see Additional file 2.

\section{Definition of subindicators}

In order to define a series of subindicators based on the selected health problems, 133 recognized experts working within the Catalan healthcare network were contacted, of whom 73 (54.9\%) responded. These respondents provided a total of 339 proposed indicators.

\section{Selection of subindicators}

All of the 339 proposed indicators were reviewed in two steps of the process (paired comparisons and consensus review). Of these, 210 indicators were rejected, 26 were accepted as proposed and 103 were accepted with some modifications.

\section{Deliberation about subindicators and final construction of the EQA}

Of the 129 indicators subjected to deliberation, 25 were discarded due to feasibility problems in their calculation. After the fusion and rejection of some indicators as described in methods (prevalence indicators and indicators that measure the same) 61 indicators were selected. So, of the 91 initial health problems, 21 in the population older than 14 years had the necessary characteristics to be evaluated in a centralized manner using the electronic medical record.

Therefore, the EQA for primary care was constructed from 61 subindicators, 39 of them dealing with the population older than 14 years and 22 targeting the paediatric population. At the level of the individual professional, the calculation incorporates just 27 of the subindicators for the population older than 14 years and 16 paediatric subindicators, since the number of cases for the rest of the indicators would not permit meaningful individual EQA calculation. Table 1 contains the indicators that comprise the EQA and their weighting and Additional file 3 contains their definitions.

In the development of subindicators for the population older than 14 years, the clinical categories for which the most indicators were established were diabetes mellitus 2 and vaccinations, with 4 subindicators in each case; these also took on the highest weighting, with 97 and 89 points, respectively. Nonetheless, the two indicators with the highest weighting were blood pressure control in patients with arterial hypertension, with 44 points, and antiplatelet/anticoagulant treatment in patients with atrial fibrillation, with 38 points.

Between 2007 and 2010, the EQA has seen some modifications in the number of paediatric indicators and the calculation of some of these. In 2010 the paediatric portion of the EQA had 26 subindicators, 20 of which are calculated at the level of the individual professional. Some of these changes resulted from suggestions received from healthcare professionals and scientific societies. For example, in the first year of EQA implementation (2007) 142 suggestions directly or indirectly related to the EQA were received and analysed. None of the modifications performed affected the definition of subindicators.

\section{Evolution of the indicators}

The current EQA is calculated in an aggregate form for 296 PCTs, representing 4340 family physicians and paediatricians, and 4082 nurses. These professionals receive monthly information updating their results on the relevant indicators. The EQA calculation uses an automatic computerized process that extracts data from electronic medical records; the results are published in a follow-up website linked to their workstation (Coma Redon and Méndez Boo 2010). Figure 1 shows the growing trend of healthcare professionals consulting their EQA results each month using the online tool. In just four years (20062010), the number of professionals accessing their results increased from 1989 in June 2006 to 6305 in December 2010; since early 2007, this number has remained between 5000 and 6000 individuals, showing a slight decrease during the summer months, an increase at year-end, and a maximum peak (6701) to date in April 2009. This means that, on average, approximately $71 \%$ of all PCT professionals for whom data are published have consulted the site once a month since 2007.

Together with this incremental use of the online tool to view EQA results, an ongoing improvement has been observed in most of the quality indicators. Figure 2 shows the number of patients diagnosed and, of these, how many met the criteria established for some key indicators among the years. In all cases, both the number of recorded diagnoses and the indicators being met have increased. Therefore, between January 2007 and December 2010 there was an increase of $230.78 \%$ in patients with an ischemic cerebrovascular accident who had good lipids control, of $33 \%$ in heart failure patients receiving an ACEI (angiotensin-converting-enzyme inhibitor) or ARB (angiotensin receptor blockers) prescription, of $26 \%$ in cases of ischemic heart disease receiving proper antiplatelet treatment, and of $21 \%$ in infants receiving all recommended vaccinations (Table 2). Figure 3 shows the 
Indicator

Ferropenic anaemia

$1 \quad$ Diagnosis of new cases 14

2

Follow-up

Social assessment

3

Of individuals who are dependent on family members 13

4

Of frail elderly individuals

Cerebrovascular disease (CVD) and/or transient ischemic attack (TIA)

Ischemic heart disease (IHD)

Hypercholesterolemia

10

Atrial fibrillation (AF)

Arterial hypertension (AHT)

12

13

Heart failure (HF)

14

15

Chronic hepatitis $C$

16

Alcohol use

17

Tobacco use

18

19

Diabetes mellitus 2 (DM2)

20

21

22

23

\section{Cognitive deterioration}

24

25

26

Impacted earwax

27

Asthma

28

Vaccinations

Blood pressure (BP) control

Screening and onset prevention

HbA1c control

Screening and prevention of diabetic retinopathy

ACEI/ARB treatment in DM2 with chronic nephropathy

Syndrome diagnosis, new cases of cognitive deterioration

Home health care interventions for a safe living environment for patients with dementia 13

Assessment of caregiver burnout 
Table 1 Structure and weighted scoring of the synthetic indicator “Healthcare Quality Standard 2007 (Continued)

\begin{tabular}{lll}
\hline 30 & Flu shots in at-risk patients & 20 \\
31 & Pneumonia shots in patients aged $\geq 60$ years & 5 \\
32 & Tetanus shots & 35
\end{tabular}

Chronic obstructive pulmonary disease (COPD)

33

Diagnosis of new cases

Home health care (ATDOM)

35

36

PREALT

37

Nephritic colic

38

Case complexity assessment of patients with ATDOM

Assessment of pressure ulcers risk

Prostate cancer

$39 \quad$ Avoid improper use of PSA 11

Clinical condition in children

Indicator

Preventive care

\begin{tabular}{|c|c|c|}
\hline 40 & Screening for congenital metabolic diseases & 7 \\
\hline 41 & Introduction of foods at recommended stages & 7 \\
\hline 42 & Systematic infant vaccinations (0-14 years) & 10 \\
\hline 43 & Control of growth and development ( $0-2$ years) & 8 \\
\hline 44 & Screening for passive smoking $\leq 2$-year-olds & 7 \\
\hline 45 & Maintenance of maternal lactation & 6 \\
\hline 46 & Measles vaccination at 13 years & 6 \\
\hline 47 & Dental cavity preventive treatment (6-12 years) & 7 \\
\hline 48 & Screening for ocular diseases ( $0-6$ years) & 8 \\
\hline 49 & Flu shots in at-risk children $<15$ years & 7 \\
\hline 50 & Screening for toxic habits (11-14 years) & 7 \\
\hline \multicolumn{3}{|c|}{ Increasing capacity to resolve cases at primary care level } \\
\hline 51 & Umbilical hernia in children $\leq 3$ years & 5 \\
\hline 52 & Contagious mollusk and viral warts ( $0-14$ years ) & 6 \\
\hline 53 & Neonatal dacryocystitis $<9$ months & 6 \\
\hline \multicolumn{3}{|c|}{ Acute disease } \\
\hline 54 & Treatment of acute gastroenteritis ( 3 months to 14 years ) & 7 \\
\hline 55 & Treatment of tonsillitis, pharyngitis or pharyngotonsillitis $<3$ years & 7 \\
\hline 56 & Treatment of acute bronchiolitis $<2$ years & 6 \\
\hline 57 & Treatment of catarrh in upper respiratory infection or flu $<15$ years & 7 \\
\hline 58 & Treatment of acute nonsuppurative otitis media (2-14 years ) & 7 \\
\hline \multicolumn{3}{|c|}{ Chronic disease } \\
\hline 59 & Diagnosis of childhood asthma (7 a 14 years ) & 8 \\
\hline 60 & Calculation of body mass index in obesity or weight gain (6-14 years) & 7 \\
\hline \multicolumn{3}{|c|}{ Social assessment } \\
\hline 61 & Social assessment of children with a disability ( $<15$ years) & 4 \\
\hline otal & & 1000 \\
\hline
\end{tabular}




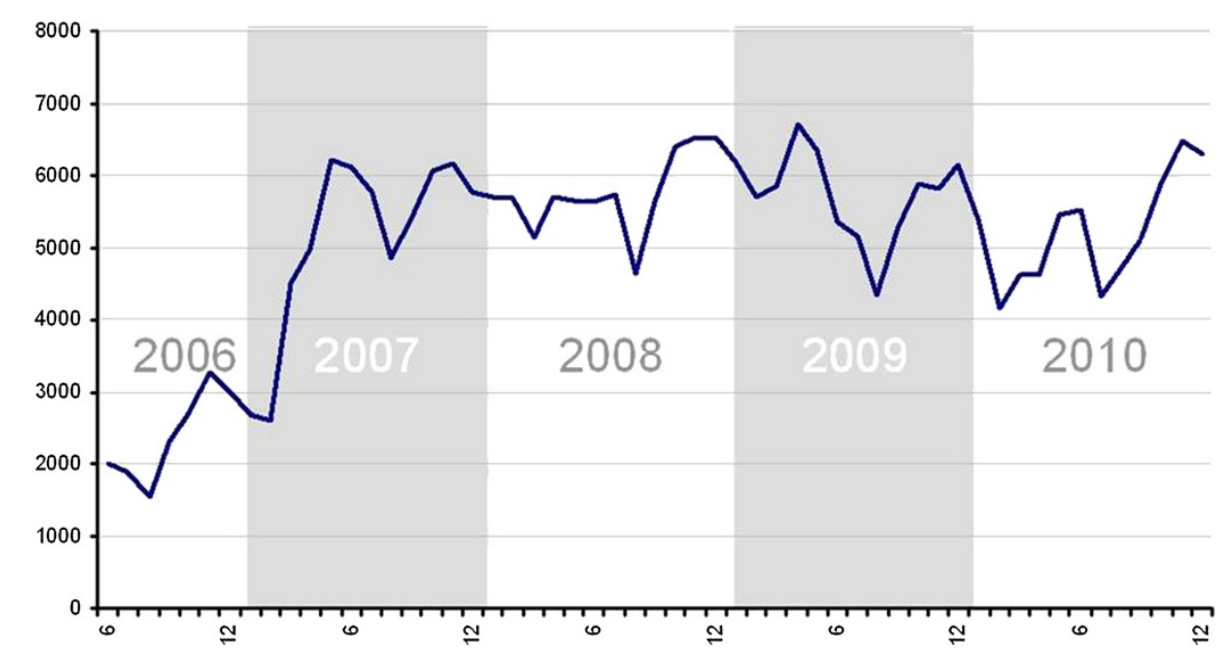

Figure 1 Number of healthcare professionals who consult their EQA quality outcomes.

evolution of the indicators performed at the level of the individual professional. In the better part of them, the rates of resolved cases have increased over the various years.

\section{Discussion and conclusions}

This article describes the methods used to create the EQA, a synthetic indicator of the quality of healthcare, and the results after four years of regularly calculating and reporting the results. The characteristics of the EQA are aligned with those described as essential for good indicators (Houghton and Rouse 2004; Bell and Levinson
2007): it is simple to calculate (the subindicators are proportions); easy to interpret, both for healthcare professionals who periodically look at their results and for various levels of management; relevant in the sense that the subindicators are based on health problems that stand out in primary care; and can be validated by feedback from healthcare professionals.

Among the strengths of the EQA, which it shares with other synthetic indicators such as SQUID (Nietert et al. 2007; Roland 2004), is that it is calculated automatically by a process that takes advantage of data contained in electronic medical records. This has advantages for the

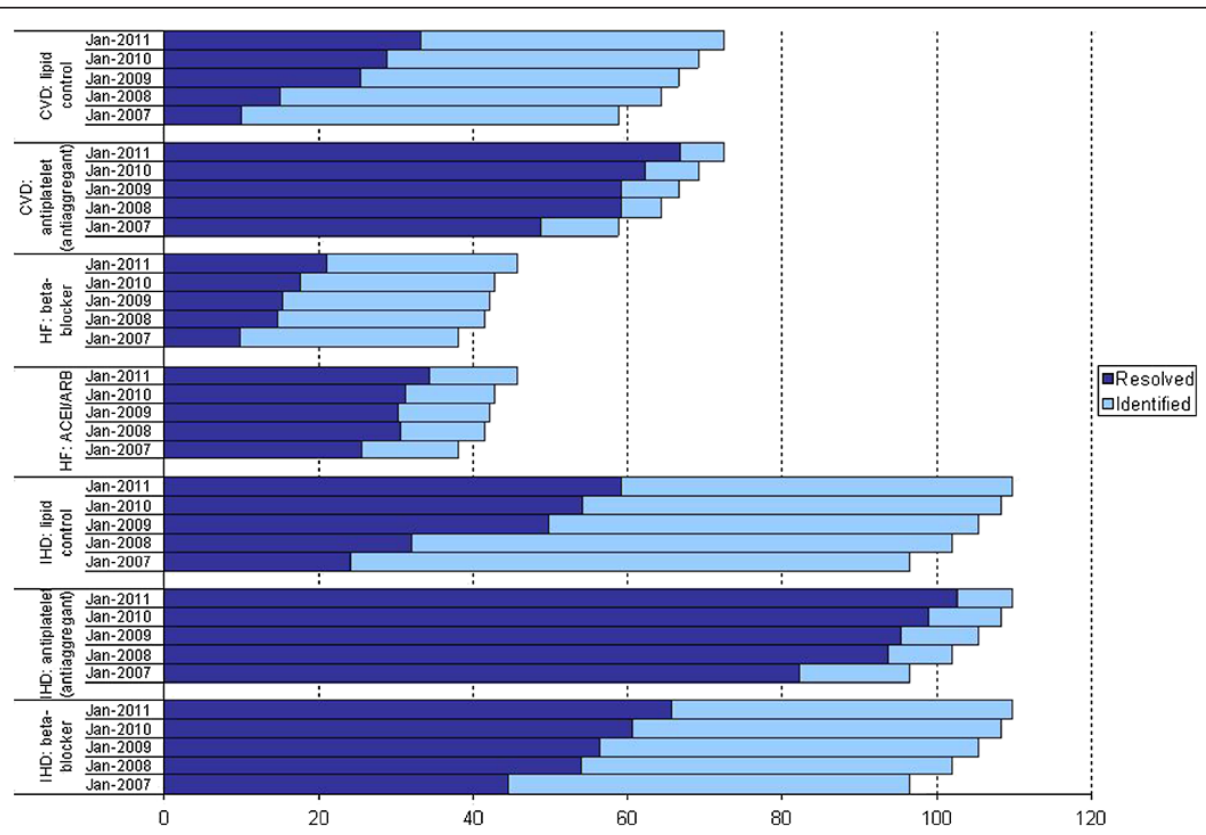

Figure 2 Examples of subindicators, with numbers of patients diagnosed and managed. 
Table 2 Difference (\%) of resolved cases between 2007 and 2010 by subindicator

\begin{tabular}{|c|c|c|c|c|}
\hline INDICATOR & January 2007 & December 2010 & Difference & $\%$ Difference \\
\hline \multicolumn{5}{|l|}{ Ischemic heart disease } \\
\hline Treatment with beta- blockers & 44,484 & 66,338 & 21,854 & 49.13 \\
\hline Treatment with antiplatelets & 82,120 & 103,482 & 21,362 & 26.01 \\
\hline Control of lipids & 24,269 & 60,105 & 35,836 & 147.66 \\
\hline \multicolumn{5}{|l|}{ Heart failure } \\
\hline Treatment with ACEI or ARB & 25,705 & 34,342 & 8,637 & 33.60 \\
\hline Treatment with beta- blockers & 9,738 & 21,073 & 11,335 & 116.40 \\
\hline \multicolumn{5}{|l|}{ Ischemic cerebrovascular accident } \\
\hline Treatment with antiplatelets & 48,851 & 67,265 & 18,414 & 37.69 \\
\hline Control of lipids & 10,127 & 33,498 & 23,371 & 230.78 \\
\hline Childhood vaccinations & 563,524 & 684,125 & 120,601 & 21.40 \\
\hline
\end{tabular}

speed and reliability of the calculation, and decreases any potential observer bias. In addition, calculating the EQA at the patient, professional and PCT levels permits the identification of patients who are poorly controlled as well as comparisons with other groups, both of patients and of healthcare professionals and centres.

Other efforts to create a synthetic indicator of healthcare quality have been described in the literature before, such as the process used to construct the QOF or SQUID. Although it was possible to use the structure of existing indicators, a new synthetic indicator was performed because of the local acceptability and difficulties in the calculation of some subindicators with existing data. However, these three indicators share certain characteristics, being based on clinical indicators focussed on health problems selected for their prevalence or relevance in terms of impact (Roland 2004; Doran et al. 2006), working with a 12month timeframe, or using a common algorithm (choose at-risk patients, determine whether they meet indicator, and calculate the result). In addition, the selection of criteria for the choice of the EQA subindicators (scientific evidence, availability, feasibility, etc.) is similar to that of SQUID, and many of the same pathologies were selected in both cases (arterial hypertension, HF, IHD, diabetes, COPD, vaccination, etc.). This should come as no surprise, precisely because both indicators are based on the most prevalent pathologies in primary care.

Among these common characteristics we would highlight the feedback from healthcare professionals, which has been very positive and useful. The EQA has been and remains under continuous development. Although there have been only small modifications in the definition of the indicators, there have been numerous changes in the manner of obtaining data, especially in the first and second years, as a result of user suggestions sent by e-mail. Thanks to the publication of EQA data and to being able to verify them using the patient lists provided, healthcare professionals have served as external validators, demanding changes in the information processing that collected data from the different types of records.

Despite similarities with other synthetic indicators, there are differences as well, such as the EQA weighting of each subindicator by its importance and, especially, the concept of exclusion. In the QOF the physician can exclude those patients considered irrelevant to an indicator. For example, the professional could exclude a patient with terminal cancer from an indicator of controlled cholesterol levels (Roland 2004; Doran et al. 2006). Such exclusions are intended to avoid unnecessary treatment by doctors seeking to improve their performance results. Nonetheless, this type of exclusion also could lead to manipulation of the results: the professional could improve the results on an indicator by improper exclusion of patients who did not meet that indicator.

There are several possible ways of addressing the problem of patients for whom some indicator is contraindicated. Doran et al. (2008) points out three possible solutions: to design indicators that incorporate all possible exceptions in their calculations, to permit healthcare professionals to exclude patients, or to set performance targets below $100 \%$. The first two options have the problem of converting the indicators into something very complicated and susceptible to fraudulent exclusions. Nonetheless, an argument in favour of patient exclusions is that if the limits for the indicators are very high, some patients may be inappropriately treated because they cannot be excluded (Doran et al. 2008). On the other hand, if the limits are too low they allow doctors to achieve the maximum score without treating all eligible patients. In our case, we did not consider the possibility of allowing healthcare professionals to exclude patients in this instance and decided to set targets below 100\%, combined with a calculation of expected prevalence, to ensure a minimum denominator (Additional file 1).

Of course, the risk of underreporting some pathologies in poorly controlled patients always exists. To avoid 

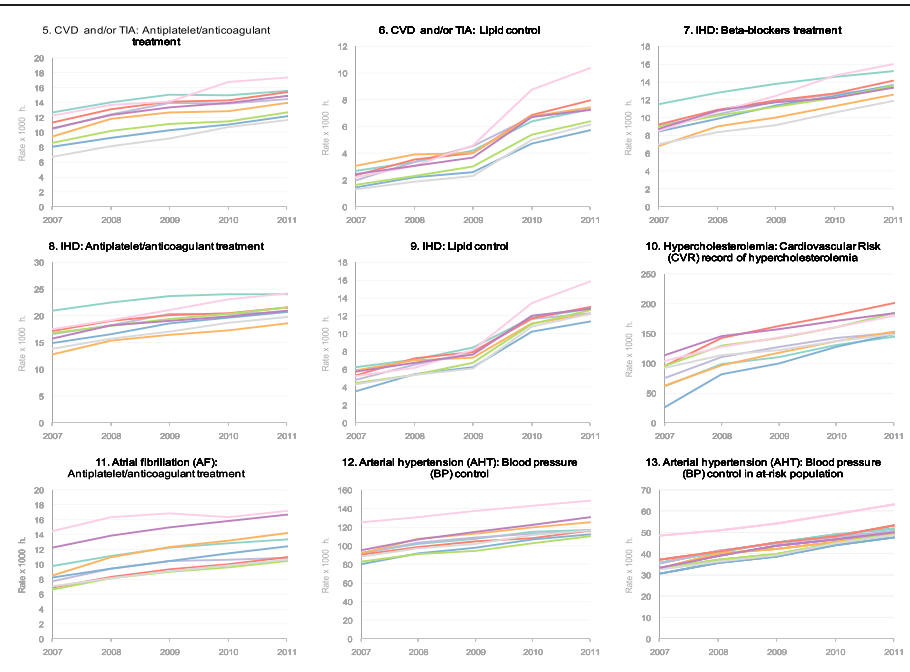

14. Heart fallure (HF): ACEUARB troatment

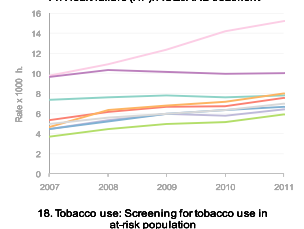

15. Heart fallure (HF): Beta-blockers treatment
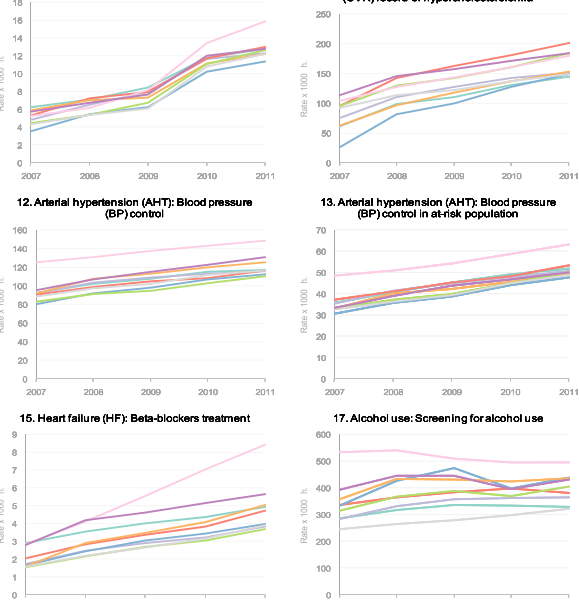

70

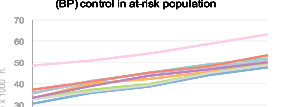

(2)

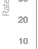

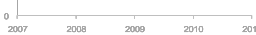

17.Alcohol use: Screening foralcohol use

${ }_{500}^{600}$

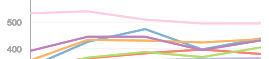

3

200
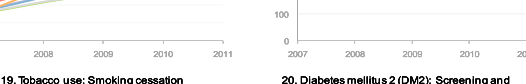

250

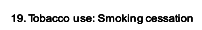

20. Dlabetes mellitus 2(DM2): Screening and
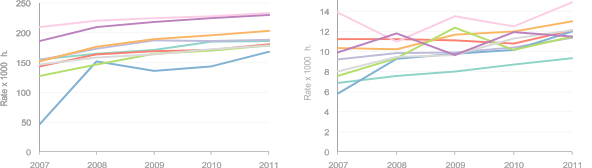

$\infty$

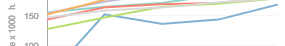

$8_{2}^{150}$

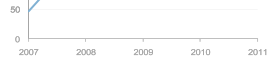

21. Diabetes mellitus 2(DM2): HBA1c control
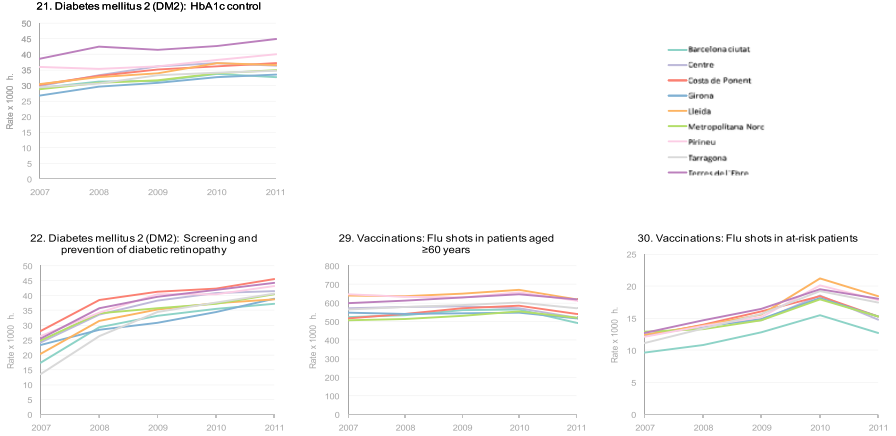

31. Vaccinations: Pnoumonia s sots in patients

33. Chronic obstructive pulmonary disease
(COPD): Diagnosis of new cases
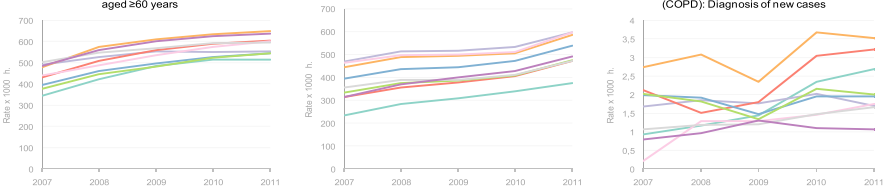

34. Chronic obstructive pulmonary disease
(COPD): Training in use of COPD inhalers
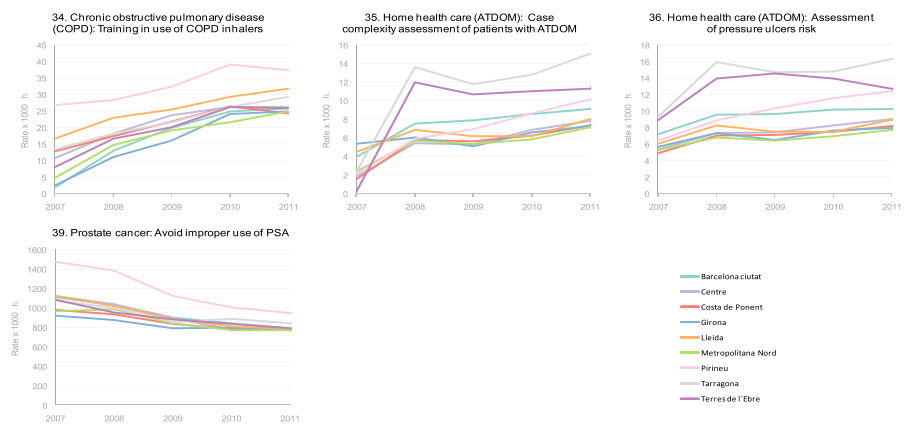

Figure $\mathbf{3}$ (See legend on next page.) 
underreporting, the QOF indicators included an audit of randomly selected doctors and of some who were suspected of fraudulent results. This is an important point because the data were entered by the doctors themselves (Doran et al. 2006). In the EQA, the information was collected directly from the medical record, so there should not be many fraudulent cases. In this sense, the development of the EQA opted for a system that could control against potential manipulation and did not demand $100 \%$ compliance with the indicator. Therefore, the concept of expected prevalence was used, which allowed us to ensure a minimum prevalence for each indicator. In addition, in order to not penalize situations such as voluntary exclusion from treatment or physician decisions based on specific cases, we determined that $80 \%$ compliance (both for expected prevalence and for resolution) would receive the total score for each subindicator. As described in the results section, the number of diagnoses (and therefore of records) has increased each year, which leads us to believe that these possible exclusions are not relevant to the EQA. Nonetheless, it could be of interest to include specific, identifiable exclusions by exploiting the electronic medical record data in these cases of evident contraindications. In this sense, we have considered incorporating these exclusions in a new version of the EQA, as long as they could be assessed in a centralized fashion.

Some authors have found that improvements in indicators linked to pay for performance were due more to increased entries in the registry than to improvements in clinical practice (Bell and Levinson 2007; Petersen et al. 2006). Nonetheless, other studies indicate that economic incentives are a potent stimulus to modify professional conduct (Gené Badia 2007), although this can only be achieved if the objectives are based on records that cannot be manipulated by the healthcare professionals. Therefore, the EQA indicators combine identification of health problems, conduct of laboratory tests, control of chronic diseases, treatments prescribed, administration of vaccines, etc. These fields are difficult to manipulate because of their relevance and variety.

Monitoring the indicators can also provoke unexpected consequences such as the deselection of patients, over-treating patients without deriving any benefit and the neglect of areas not covered because of lack of information (Kerr and Fleming 2007). In this sense, a common criticism of quality indicators linked to pay for performance is that healthcare professionals will focus exclusively on these and not pay attention to other important aspects of clinical practice (Lester and Majeed 2008; Bell and Levinson 2007). Although this outcome is difficult to assess and inherent to all indicators linked to pay for performance, more studies are needed to allow us to quantify the importance of this limitation.

Finally, it is important to point out that the EQA reflects only a small part of the work of primary care professionals, that part that can be measured. Other important but non-quantitative dimensions or pathologies such as mental illness or acute pathologies are difficult to measure and are not included in the EQA. This limitation is also found in other synthetic indicators such as the QOF (Roland 2004), where the indicators represent only part of clinical practice. The underreporting of certain conditions is therefore common to all databases but need not impede our continuing efforts to improve the registry and eventually incorporate other aspects of primary care that cannot be readily evaluated with the resources available to us today.

\section{Additional files}

Additional file 1: Calculation and components of the synthetic indicator.

Additional file 2: Health problems groups, codes included and encounter rate by 1000 patients.

Additional file 3: Definition of subindicators of the EQA.

\section{Abbreviations}

ACEl: Angiotensin-converting-enzyme inhibitor; AF: Arterial fibrillation; AHT: Arterial hypertension; ARB: Angiotensin receptor blockers;

ATDOM: Home health care; BP: Blood pressure; CVD: Cerebrovascular disease; COPD: Chronic obstructive pulmonary disease; CVR: Cardiovascular risk; DM2: Diabetes mellitus 2; eCAP: Electronic health record in Catalonia; EQA: Estàndard de Qualitat Assietncial (Healthcare quality standard); HF: Heart failure; ICD-10 code: International Classification of Diseases; ICS: Institut Català de la Salut (Catalan Institut of Health); IHD: ischemic heart disease; NHS: National Health Services; NCMC: Non-compensatory multicriteria approach; PCT: Primary care teams; PSA: Prostate-specific antigen; QMAS: Quality Management and Analysis System; QOF: Quality Outcomes Framework; SISAP: Sistema d'Informació dels Serveis d'Atenció Primària (Information System for Primary Care Services); SQUID: Summary Quality Index; TIA: Transient ischemic attack.

\section{Competing interests}

The authors declare that they have no competing interests.

\section{Authors' contributions}

EC contributed to perform and publish the EQA, perform the analysis of data and drafted the manuscript. MF, BI and MM contributed to design the EQA and define indicators, and helped draft the manuscript. LM and FF contributed to design, performed and publish the EQA, define indicators and helped draft the manuscript. All authors have read and approved the final manuscript. 


\section{Acknowledgements}

We thank all the professionals involved somehow in the process of creating the EQA, specially to Josep Casajuana; Edurne Zabaleta; Eugeni Fau; Sebastia Calero; Josep M. Argimón; Rosa Morros; Joan Carles Contel; Mireia Fàbregas; Carles Garcia Gonzalo; Francisco Martín Lujan; Josep Aubà; Ricard Carrillo; Anna Ribas; Hèlia Cebrian; Núria Hernández; Asunción Aguas; Joan Antoni Ponsà; Ester Amado; Pere Joan Cortes; Neus Parellada; Teresa Masat Ticó; Montse Torres; Modest Masdeu; Montse Nozal; Alícia Aguiló; Manel Enrubia; Eduardo Ortega; Silvia Cutillas; Gemma Rodríguez; Vicente Morales. Translation to english of this paper has been supported by IDIAP Jordi Gol. We thank Elaine M. Lilly for her valuable contribution to translation and copy editing of the manuscript.

\section{Author details}

IInstitut Català de la Salut (ICS), Gran Via de les Corts Catalanes, 587-589, 08007, Barcelona, Spain. ${ }^{2}$ IDIAP Jordi Gol (Primary Health Care Research Institute), Gran Via de les Corts Catalanes, 587, 08007, Barcelona, Spain. ${ }^{3}$ Unitat Docent de Barcelona, Institut Català de la Salut (ICS), C/ Sant Elies 42 08006, Barcelona, Spain. ${ }^{4}$ EAP Vilanova 3 CAP Baix a Mar, Consorci de Serveis a les Persones, Plaça Boleranys, 5, 08800, Vilanova i la Geltrú, Spain.

Received: 13 November 2012 Accepted: 4 February 2013

Published: 13 February 2013

\section{References}

Bell C, Levinson W (2007) Pay for performance: learning about quality. CMAJ 176 (12):1717-1719

Brown C, Lilford R (2006) Cross sectional study of performance indicators for English Primary Care Trusts: testing construct validity and identifying explanatory variables. BMC Health Serv Res 6:81

Coma Redon E, Méndez Boo L (2010) SISAP: 4 años buceando en mares de datos. AMF 6(8):473-476

Cortés Pérez PJ, Mendez Boo L, Fina Avilés F, Ferran Mercadé M, Iglesias Pérez B, Medina Peralta M, Casajuana Brunet J, Calero Muñoz S, Fabrellas Padrés N, Morros Pedrós R, Catalán Ramos A, Vidal Milla A (2009) Documents de Direcció per objectius dels equips d'atenció primària 2009. Institut Català de la Salut, Barcelona. [http://www.gencat.cat/ics/professionals/pdf/DPO 2009.pdf]

Doran T, Fullwood C, Gravelle H, Reeves D, Kontopantelis E, Hiroeh U, Roland M (2006) Pay-for-Performance Programs in Family Practices in the United Kingdom. N Engl J Med 355:375-384

Doran T, Fullwood C, Reeves D, Gravelle H, Roland M (2008) Exclusion of Patients from Pay-for-Performance Targets by English Physicians. N Engl J Med 359:274-284

Eccles M, Freemantle N, Mason J (1998) North of England evidence based guidelines development project: methods of developing guidelines for efficient drug use in primary car. BMJ 316:1232

Engels Y, Campbell S, Dautzenberg M, Van den Hombergh P, Brinkmann H, Szécsényi J, Falcoff H, Seuntjens L, Kuenzi B, Grol R (2005) Developing a Framework of, and quality indicators for, general Management in Europe. Fam Pract 22:215-222

Fina Avilés F, Mendez Boo L, Coma Redon E, Medina Peralta M (2010) Sistema de Información de los Servicios de Atención Primaria (SISAP). La experiencia 2006-2009 de l'Institut Català de la Salut. Revista de Innovación Sanitaria y Atención Integrada 2:1, Article 2

Gené Badia J (2007) Basta de <<clicar>> casillas. Aten Primaria 39(4):169-170

Gérvas J, Pérez M (2008) Pago por desempeño ("pay for performance" [P4P]). AMF 4(6):344-352

Houghton G, Rouse A (2004) Are NHS primary care perfomance indicator scores acceptable as markers of general practitioner quality? Br J Gen Pract 54:341-344

Iglesias Pérez B, Cortés Pérez P, Fina Avilés F, Mendez Boo L, Ferran Mercadé M, Medina Peralta M (2008) Indicador sintètic de qualitat assistencial (EQA) dels equips d'atenció primària 2008. Institut Català de la Salut, Barcelona. [http:// www.gencat.net/ics/professionals/pdf/EQA_2008.pdf]

Kerr E, Fleming B (2007) Making performance indicators work: experiences of US Veterans Health Administration. BMJ 335:971-973

Lester H, Majeed A (2008) The future of the quality and outcomes framework. BMJ 337:a3017

McColl A, Roderick P, Gabbay J, Smith H, Moore M (1998) Performance indicators for primary care groups: an evidence based approach. BMJ 317:1354-1360

Medicare Australia (2999) Practice Incentives Program (PIP). [www. medicareaustralia.gov.au/provider/incentives/pip/index.jsp]
NHS Institute for Innovation and Improvement (2999) The Good Indicators Guide: Understanding how to use and choose indicators. [www.apho.org.uk/ resource/view.aspx?RID=44584]

Nietert PJ, Wessell AM, Jenkins RG, Feifer C, Nemeth LS, Ornstein SM (2007) Using a summary measure for multiple quality indicators in primary care: the Summary Quality Index (SQUID). Implementation Science 2:2-11

Peiró S (2004) Los indicadores deben bajar a las trincheras. Rev Calidad Asistencial 19(6):361-362

Perera R, Dowell T, Crampton P, Kearns R (2007) Panning for gold: An evidencebased tool for assessment of performance indicators in primary health care. Health Policy 80(2):314-327

Petersen LA, Woodard LD, Urech T, Daw C, Sookanan S (2006) Does pay-for -performance improve the quality of health care? Ann Intern Med 145 (4):265-271

Pink GH, Brown AD, Studer ML, Reiter KL, Leatt P (2006) Pay-for-performance in publicly financed healthcare: some international experience and considerations for Canada. Healthc Pap 6:8-26

Roland M (2004) Linking physicians' pay to the Quality of Care - A Major Experiment in the United Kingdom. N Engl J Med 351:1448-1454

Rosenthal MB, Frank RG, Li Z, Epstein AM (2005) Early experience with pay-for -performance: from concept to practice. JAMA 294:1788-1793

Saturno PJ (2004) La invasión de los indicadores compuestos. Riesgos y beneficios para la gestión de la calidad. Rev Calidad Asistencial 19(6):407-415

The Ambulatory Care Quality Alliance Recommended Starter Set (2999) Clinical Performance Measures for Ambulatory Care. Agency for Healthcare Research and Quality, Rockville MD. [http://www.ahrq.gov/qual/aqastart.htm]

Vila A, Ansa X, Gómez A, Fort J, Grifoll J, Pascual I (2006) EQA-17: propuesta de un indicador sintético del producto de la atención primaria en mayores de 14 años. Rev Esp Salud Publica 80(1):19-28

doi:10.1186/2193-1801-2-51

Cite this article as: Coma et al:: Creation of a synthetic indicator of quality of care as a clinical management standard in primary care. SpringerPlus 2013 2:51.

\section{Submit your manuscript to a SpringerOpen ${ }^{\odot}$ journal and benefit from:}

- Convenient online submission

- Rigorous peer review

- Immediate publication on acceptance

- Open access: articles freely available online

- High visibility within the field

- Retaining the copyright to your article

Submit your next manuscript at $\gg$ springeropen.com 